\title{
Towards a method for the economic evaluation of environmental indicators in UK Integrated Arable Farming Systems
}

Article

Accepted Version

Bailey, A., Rehman, T. U., Park, J., Keatinge, J.D.H. and Tranter, R. (1999) Towards a method for the economic evaluation of environmental indicators in UK Integrated Arable Farming Systems. Agriculture, Ecosystems and Environment, 72 (2). pp. 145-158. ISSN 0167-8809 doi:

https://doi.org/10.1016/S0167-8809(98)00171-6 Available at https://centaur.reading.ac.uk/25395/

It is advisable to refer to the publisher's version if you intend to cite from the work. See Guidance on citing.

To link to this article DOI: http://dx.doi.org/10.1016/S0167-8809(98)00171-6

Publisher: Elsevier

All outputs in CentAUR are protected by Intellectual Property Rights law, including copyright law. Copyright and IPR is retained by the creators or other copyright holders. Terms and conditions for use of this material are defined in the End User Agreement. 


\section{CentAUR}

Central Archive at the University of Reading

Reading's research outputs online 


\title{
1 Towards a method for the economic evaluation of environmental
}

\section{indicators for UK integrated arable farming systems}

${ }^{\mathrm{b}}$ Department of Agriculture, The University of Reading, Earley Gate, PO Box 236, Reading, Berkshire,

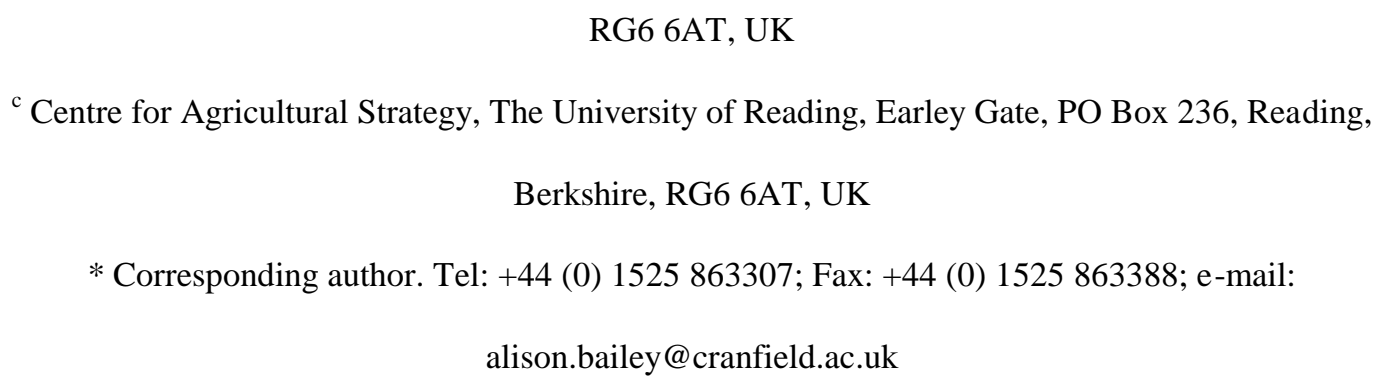

${ }^{c}$ Centre for Agricultural Strategy, The University of Reading, Earley Gate, PO Box 236, Reading, Berkshire, RG6 6AT, UK

* Corresponding author. Tel: +44 (0) 1525 863307; Fax: +44 (0) 1525 863388; e-mail:

alison.bailey@cranfield.ac.uk

\begin{abstract}
Integrated Arable Farming Systems (IAFS), which involve a reduction in the use of off-farm inputs, are attracting considerable research interest in the UK. The objectives of these systems experiments are to compare their financial performance with that from conventional or current farming practices. To date, this comparison has taken little account of any environmental benefits (or disbenefits) of the two systems. The objective of this paper is to review the assessment methodologies available for the analysis of environmental impacts. To illustrate the results of this exercise, the methodology and environmental indicators chosen are then applied to data from one of the LINK - Integrated Farming Systems experimental sites. Data from the Pathhead site in Southern Scotland are used to evaluate the use of invertebrates and nitrate loss as environmental indicators within IAFS. The results suggest that between 1992 and 1995 the biomass of earthworms fell by $28 \mathrm{~kg}$ per hectare on the integrated rotation and rose by $31 \mathrm{~kg}$ per hectare on the conventional system. This led to environmental costs ranging between $£ 2.24$ and $£ 13.44$ per hectare for the integrated system and gains of between $£ 2.48$ and $£ 14.88$ for the conventional system. In terms of nitrate, the integrated system had an estimated loss of $£ 72.21$ per hectare in comparison to $£ 149.40$ per hectare on the conventional system. Conclusions are drawn about the advantages and disadvantages of this type of analytical framework.
\end{abstract}




\section{Introduction}

The impact of agricultural systems on the environment is of increasing concern generally, and there is a growing body of research into the quantification of environmental benefits and disbenefits resulting from agriculture and other rural industries. However, little work has concentrated on the valuation of environmental benefits and disbenefits at the farm level with few considering the trade-off between financial and environmental impacts.

11 The objective of this paper is to provide insights into possible approaches to both the valuation of environmental benefits and disbenefits at the farm level and the resultant trade-offs between financial and environmental impacts. This is achieved through the use of data from a case-study farm at Pathhead in Southern Scotland.

15 This farm is part of the LINK Integrated Farming Systems (IFS) Project (Ogilvy et al., 1994), a five-

16 year rotational systems experiment which was established to compare conventional and integrated arable farming systems in six different agro-ecological zones around Great Britain. The main objective

18 of the LINK-IFS experiment was to test the practical and financial feasibility of such systems whilst 19 taking into account the level of inputs being used and their environmental impact. As a result, they 20 were able to provide the financial and environmental data for use in this study, which starts with a brief 21 review of the assessment methodologies and trade-off frameworks used in the analysis.

\section{Environmental economic modelling}

\subsection{Overview}

25 Analysis of the trade-off between financial returns from farming and its environmental impact is based 26 on the use of combined environmental economic models, providing a framework that allows both 27 conventional agricultural production and the production of externalities (Wossink et al., 1996).

28 Farming systems can therefore be analysed from both financial and environmental viewpoints to evaluate trade-offs between the two criteria. 
$1 \quad$ Early examples are provided by the materials balance framework of Ayres and Kneese (1969) and 2 input-output analysis developed by Leontief (1970). Both approaches successfully highlighted some 3 interactions between the economy and the environment offering convenient classifications for 4 environmental impacts at various stages of economic activity. More recent examples are from environmental impact assessment (EIA) (Glasson et al., 1994). EIA deals with four key problem areas: identification, prediction and measurement, interpretation, and communication. Impact identification techniques (Bisset, 1983, 1988; Wathern, 1984) date from the 1970s and include checklists (Dee et al., 1972), networks (Sorenson, 1971), and matrices (Leopold et al., 1971). They provide a simple enumeration of the impacts of an action, concentrating on pollution and soil erosion and, to a lesser extent, social impacts such as recreation and employment. Economic considerations are 11 virtually ignored and they tend to not give the probability, importance or magnitude of the likely impacts of an activity.

13 Key concepts involved in the measurement of environmental impacts are scoring to standardise the 14 information for comparative purposes using qualitative or quantitative methods and weighting to reflect 15 the relative importance of different impacts. Possible approaches to measurement and valuation include the construction of indices (e.g., Kelly et al., 1996), energy use analysis (e.g., Taylor et al., 1993) and monetary valuation. Pearce et al. (1989a) argue that it is important to place monetary measures on environmental gains and losses for capturing the intensity of preference and degree of concern for the environment. Extensive literature exists on the economic valuation of the environment covering both theory (e.g., Pearce et al., 1989b; Meister, 1990) and also practical applications (e.g., Dixon and Sherman, 1990; James, 1994). Identification of impacts and their measurement or valuation are then combined in the environmental economic models. Cost benefit analysis (CBA) and multi criteria analysis (MCA) are the most common such approaches.

24 CBA applies monetary values to all costs and benefits resulting from an action to be undertaken (Mishan, 1975). It is particularly useful in identifying and measuring the impacts of projects or policies to provide a criterion to judge projects given the objectives set, whether economic, social or environmental. However, there are problems in the identification, enumeration and putting monetary values on intangibles. Value judgements also have to be made to evaluate impacts in the absence of adequate market prices. 
MCA is a set of procedures, based on mathematical programming, designed to help choose between options (Romero and Rehman, 1987, 1989) particularly, for estimating the effects of alternative policy measures on financial returns and the environment. The advantage of MCA is that it permits simultaneous consideration of multiple decision criteria, unlike single objective linear programming (LP), without the need to specify incommensurable criteria in a common metric of monetary values. Alongside current interest in MCA is the considerable amount of work on environmental and natural resource accounting (see Ahmad et al., 1989; Lutz, 1993; United Nations, 1993). Such accounting is a comprehensive incorporation of the environmental impacts into the system of national accounts to allow the assessment of the trade-offs between the benefits and disbenefits of production and consumption activities. These approaches provide a coherent picture of resource use and depletion or increase, which can be linked to, or integrated with, the national accounts (Bartelmus, 1989). Two examples are the Norwegian system of resource accounting (Alfsen et al., 1987) and the French patrimony accounts (Theys, 1989).

\subsection{Suitability for the analysis of Integrated Arable Farming Systems}

Considering the problem of evaluating environmental consequences from Integrated Arable Farming Systems (IAFS) in relation to financial return, and in comparison with other farming systems, the most appropriate approach has to incorporate an assessment of both these factors. The above methods achieve this objective, some providing useful insights into the valuation of environmental impacts, others providing frameworks in which trade-offs between environmental impacts and the financial return of the farming systems can be easily identified. Of particular interest is the use of environmental and natural resource accounting as it provides an assessment framework already well-established and understood. Furthermore, the financial analysis of farming systems, already uses this approach and the expansion of these accounts to incorporate environmental considerations is a logical step forward.

Arguments in support of this approach include the use made of traditional accounting systems for analysis and forecasting, as well as policy formulation. First, economic accounts are traditionally used and it is argued that all economic activity should be taken into consideration. This includes the use of the natural environment and its incorporation occurring alongside traditional accounting activities. Second, there is the requirement for a consistent, reliable and comparable data set which can be used 
1 particularly true regarding current interest in more sustainable farming systems, as the national accounts exclude the environment and natural resource base which thus may encourage unsustainable levels of production and consumption. Third, the accounting approach provides a framework for both farm level analysis and subsequent macro level analysis and, given the current lack of research on practical applications of accounting techniques to evaluating the environment, it is a method which merits further exploration.

\section{Methodology and Approaches}

\subsection{Integrated agriculture}

Integrated agricultural production has been defined by El Titi et al. (1993) as An holistic pattern of land use which integrates natural resources and regulation mechanisms into farming practices to achieve maximum but stepwise replacement of off-farm inputs to secure quality food and to sustain income.

IAFS have attracted a great deal of research interest in the UK. They have implications for the management of farmland as they involve more complex and often longer rotations, changes in cultivations (especially the adoption of non-inversion tillage) and a reduction in the level of both pesticide and fertiliser use, if appropriate. Such practice is, in part, related to the aim of improving habitats and thus biodiversity at the whole farm level, which clearly would influence the decisionmaking processes related to husbandry practices and expectations of financial rewards on farms (Park et al., 1997).

\subsection{The experiment at Pathhead farm}

Pathhead farm is some $15 \mathrm{~km}$ south-east of Edinburgh, Southern Scotland (latitude $56^{\circ} \mathrm{N}$ ) on loam/clay loam soils of the Winton Association. The mean 30-year rainfall is $860 \mathrm{~mm}$ per annum. Full details of the experiment are provided by Fisher et al. (1996).

The conventional crop rotation at the farm reflected standard commercial farming practice in the local (Lothian and Borders) region in the early 1990's namely: winter oilseed rape (Brassica rapus) (phase 1), winter wheat (Triticum aestivum) (phase 2), set-aside (phase 3), winter wheat (phase 4), and winter barley (Hordeum vulgare) (phase 5). The integrated rotation is spring oilseed rape (phase 1), winter wheat (phase 2), set-aside (phase 3), winter wheat (phase 4), and spring barley (phase 5). The main 
1 difference between the two systems is that the integrated system had spring, rather than winter, oilseed rape in phase 1 of the rotation and spring barley instead of winter barley in phase 5 .

3 The change to spring cropping enabled savings in nitrogen fertiliser use from some $160 \mathrm{~kg} \mathrm{ha}^{-1}$ under

4 the conventional rotation to around $120 \mathrm{~kg} \mathrm{ha}^{-1}$ on the integrated rotation. Similarly, the more careful use of pesticides under the integrated system led to a reduction in active ingredient applied from 2.81 to

$6 \quad 1.55 \mathrm{~kg} \mathrm{ha}^{-1}$ (Fisher et al., 1996).

\subsection{Application to the appraisal of Integrated Arable Farming Systems}

9 The framework for the environmental and natural resource accounting model needs to incorporate two 10 perspectives for the evaluation of IAFS: the financial account for agricultural production activities and 11 a parallel account for environmental impact. These then need to be combined within an integrated environmental and economic account to illustrate the traditional financial impact of conventional farm practices and IAFS alongside their environmental impacts.

\subsubsection{Financial data}

16 The output from agriculture is conventionally measured in financial terms. Farm income, or profit, on 17 arable farms is a function of yield, crop price, area payments, and the costs directly influenced by 18 management variables such as input choices and levels of fertiliser and pesticide use and cultivation practices. Conventional farm accounts are, therefore, the main criteria for measuring the financial viability of agricultural systems. However, for a thorough analysis of the productivity of agricultural systems the effect of the economic environment, markets and subsidies, natural environment, particularly climatic conditions, and social environment also need to be taken into consideration in the use of these accounts.

\subsubsection{Environmental data}

Identifying criteria to illustrate the impact of agriculture on the environment is more problematic.

27 They need to be measurable, derived objectively, verifiable, and replicable and, given that it is currently impossible to measure all environmental impacts, they should ideally be proxies for other processes. Indicators which measure changes in key processes or highlight areas of concern are commonly used.

30 Areas of concern include changes in: amenity; soil quality; water quality and quantity; atmospheric 
1 quality; and habitat and wildlife as a result of land use and chemical inputs. Concern about energy use may also be considered as an environmental issue.

At the individual farm level, important indicators include the amenity and landscape value associated with the farming system, the impact on soil quality through the direct use of the land resource, the impact of chemical use, i.e., fertilisers and pesticides, and the resultant impacts on water quality (resources), atmosphere and biodiversity. Given that data on the amenity aspects of both the conventional and integrated systems of the LINK IFS project have not been recorded, with the assessments concentrating on the within-field aspects, this paper will now concentrate on the latter indicators which reflect, loosely, the three main economic functions of the environment: as a source of raw materials; as a sink for waste assimilation; and as a provider of environmental services.

\subsubsection{The environment as a source of raw materials}

Soil is the main physical medium for agriculture and is the site of many complex transformation processes. Assessment of soil quality regarding the demands made on this resource over time is important and should cover physical, chemical and biological criteria. Examples of indicators that are used to assess soil quality include organic matter, acidity and the levels of phosphorous, potassium, and heavy metals in the soil (e.g., Department of the Environment, 1996).

Bio-indicators such as invertebrates and, in particular, earthworm numbers and/or biomass can also be used. Such data were collected in the LINK IFS experiment. Earthworms are important to soil fertility and structure as they play a key role in trash burial, nutrient cycling, soil aeration and drainage (Lee, 1985). They are also a useful indicator as they are sensitive to a range of short-term agricultural activities (Edwards and Lofty, 1972; Edwards and Bohlen, 1996).

The economic value of earthworms is a problem, but potentially solvable as there is an actual open market value for earthworms based on their costs of production. Alternatively, as the market price may be considered a high estimate, a value could be derived by econometric techniques to extract the effect that earthworms have on crop output, through their influence on soil quality. A problem with this approach is that it is considered more appropriate to crops planted into soil that has not been cultivated (Edwards and Bohlen, 1996). However, a provisional estimate may be obtained using the difference in cost between ploughing and minimal tillage practices, assuming that the difference equates to the value 
1 of the soil structuring service provided by earthworms. It is recognised that this is only an estimate and

2 that ploughing enables rates of trash burial, mineralisation and aeration far in excess of that achievable

3 by earthworms in a season.

\subsubsection{The environment as a sink for waste assimilation}

6 Concerns regarding water quality include chemical, biological and physical aspects and are

7 highlighted in the criteria for the 1985 River Quality Classification (Department of the Environment,

8 1986), which include dissolved oxygen, biological oxygen demand (BOD), ammonia, toxicity to fish,

9 and visible signs of pollution. Additional indicators include nitrate and pesticide use, nitrate,

10 phosphorous and pesticide concentrations in water, pollution incidents, and water treatment expenditure

11 (e.g., Department of the Environment, 1996; OECD, 1997).

12 Nitrogen fertiliser is an important agricultural input, vital to the growth of plants in terms of both the 13 quantity and quality of yield. Its impact on surface and groundwater through nitrate leaching has 14 become a major environmental issue over the last decade (see Addiscott et al., 1991), and it is 15 acceptable to use nitrate levels as an indicator to estimate the environmental impact of agricultural 16 systems on water quality. Nitrate residues in the soil after harvest (autumn) provide a measure of 17 leaching risk. In order to calculate the economic value of nitrate lost from the system, it is assumed that 18 all the residue in the soil is leached from the system. The environmental damage cost incurred as a 19 result of this leaching is then taken to be equal to the costs of treating the pollution. The cost incurred 20 should not be applied to every kilogram of nitrate lost from the system, but to that above a threshold 21 level as there is some naturally occurring leakage of nitrate from the soil irrespective of management 22 practice. The environment also has the potential to assimilate some waste without damage being 23 incurred.

24 Pesticide levels are another indicator of environmental impact on water quality. Concern regarding 25 their use and effect on both human health and the environment has recently increased. However, there 26 is little work on the quantities of pesticide applied in relation to the amounts occurring in water sources 27 so it is more appropriate to concentrate on the actual level of pesticide use. Both direct and indirect 28 impacts need to be considered; direct impacts on target and non-target flora and fauna, and indirect 29 impacts where pesticides are caught up in the food chain affecting species further along that chain. The 
1 economic value of this indicator is problematic, although it could be related to the effect of the chemical on biodiversity.

3

\subsubsection{The environment as a provider of services}

5 Biodiversity, an increasingly important indicator of environmental quality, is a measure of the number

6 of different species present within a given area, taking into account the number of representatives of each species present and the variety of habitats that exist within that area. Measures of biodiversity include the percentage of species at risk, number and population changes in important species groups, and a consideration of habitats (Department of the Environment, 1996; OECD, 1997).

10 To assess individual farms and particular agricultural practices, it is important to choose an indicator 11 representative of those practices. Usual indicators include the number and population changes in mammals, birds and butterflies appropriate at the whole farm level. For the LINK IFS experiment,

13 which is comparing two systems within a single field, an indicator which is relatively immobile and, 14 affected by specific within field differences is more appropriate. Data on the number of invertebrates 15 caught by pitfall traps within each experimental plot are used as one indicator in the LINK-IFS 16 experiments. These can be considered as relevant indicators as they are part of a complex food web. In 17 terms of the economic valuation of biodiversity (Spash and Hanley, 1994; Hanley et al., 1994) there are 18 few applications in the UK all involving the use of the contingent valuation method (CVM). Related to this is the Delphi technique, an established mechanism for collecting expert opinion, which can be very

20 effective in acquiring information on values from participants who possess technical knowledge. It also 21 has the advantage that it can be undertaken in a short time period relatively cheaply. An alternative 22 approach is to relate the value of beneficial insects to the cost saving from reduced pesticide use. This assumes that pesticides are a replacement for natural ecosystem resilience.

\section{Results}

Using data from one of the sites in the LINK IFS experiment, the accounting framework is used here to compare the impact of conventional and integrated arable farming systems on financial returns and the environment. As stated in the introduction, this is a five year rotational systems experiment, with each phase of the rotation represented in every year. The data presented include both traditional financial results and the environmental data. 


\subsection{Financial results}

Table 1 provides a summary of the financial results for the five years of the experimental rotation at the Pathhead site in Southern Scotland. Output is calculated by multiplying the yield by the average November price (from the HGCA Weekly Digest) for each crop in each year plus the area payment for that year. Costs, which were already standardised as part of the main LINK-IFS project, are based on material supplied by Mr D. Harris, ADAS (Personal Communication). The aim of these results is to reflect the value of agricultural production to the farmer. They show that, in traditional financial terms, the integrated system does marginally better than the conventional system over the five years of the rotation shown with gross and net margins per hectare of $£ 3840$ and $£ 2921$ respectively. Output is lower, a result of substantially lower yields in the spring rape crop, and occasionally slightly lower yields in the cereal crops. However, the total variable costs are also lower, mainly as a result of reductions in chemical use. Cultivation costs are also lower. These lower costs give rise to the better gross and net margins on the IAFS.

Table 2 presents the same information using world prices (mid-November prices from the HGCA Weekly Digest) and without area payments to reflect the social value of agricultural output from the two systems via the removal of government intervention. Phase 3, set-aside, is also excluded from the rotation. In using world prices, it is assumed that the use and subsequent management of inputs into the two systems remains unchanged, and that crop choice, despite changing prices, also remains unchanged. Furthermore, using world prices for crop products and not for crop inputs may provide an overestimate of output where there are tariffs and subsidies on the imports of inputs. Nevertheless, given the problem in determining the combination of inputs in the absence of support, the use of world prices alongside the exclusion of area payments to provide the social value of agricultural output is a reasonable assumption. This results in a lower gross margin for the integrated system compared with the conventional system, and a smaller difference between the two for the net margin.

\subsection{Environmental results}

28 The subsequent tables provide information on the environmental data being considered. These 29 include information on the causes of environmental degradation, i.e., the use of nitrogen fertiliser and pesticides (Table 3), and the effects that these are believed to generate. The indicators chosen to 
1 represent these impacts are, respectively, earthworm (Lumbricidae) biomass (Table 4), nitrate loss

2 (Table 5), and invertebrate (beetle (Carabidae) and spider (Arachnida)) numbers (Table 6).

3 Cultivation practices at the Pathhead site, a further cause of impact on the environment, are unchanged

4 between the two systems. In terms of the economic valuation of the environmental impact of the two systems, it is only the latter indicators themselves that would need to be valued, the causes of those impacts (cultivation practices and chemical use) indicating only the potential impact.

\subsubsection{Chemical use}

Data on the use of chemicals in both the conventional and integrated system were recorded for each plot at the time of application, the overall aim being to reduce these inputs where appropriate. In the conventional system, nitrogen was applied according to conventional farm practice (i.e., farm manager's rate). For the integrated system, Scottish Agricultural College (SAC) recommendations were used, reduced for those fields where February mineral $\mathrm{N}$ measurements were high. In latter years, the correction for soil mineral $\mathrm{N}$ was halted as validation trials showed that the integrated rate was consistently too low to maximise profit. Nevertheless, applications for comparable wheat crops on the integrated system were always lower than on the conventional. Applications were also lower for the spring crops. SAC recommendations were used for $\mathrm{P}$ and $\mathrm{K}$ applications throughout, reductions occurring on the integrated system where spring crops replaced winter crops.

In relation to the use of pesticide, cereal crops on the integrated system were chosen for their disease resistance, with the use of fungicides being modified accordingly. Routine spraying was carried out on the conventional system. The same is true for herbicide applications, there being no use of autumn residual herbicide on the integrated wheat crops, whereas the conventional wheat had one application when soil conditions allowed access. Insecticides were generally not used on either system. The conventional wheat crop had routine treatment for slugs following winter oilseed rape; this was not needed for the wheat following the spring rape crop, although some spot treatment was used as necessary.

Table 3 summarises the chemical use in both systems. As is to be expected, it shows that the use of nitrogen fertiliser on the integrated system in comparison with conventional practice is reduced. This is primarily as a result of the inclusion of spring crops in the rotation, although as stated above, 
1 units used in each system, a unit being the maximum amount (in grams) of an active ingredient recommended for arable crops. As outlined above, reductions in the use of all pesticides are achieved for all chemicals (except seed dressings) in all years and for all crops on the integrated rotation with few exceptions.

\subsubsection{Earthworm biomass}

Table 4 presents information on earthworm biomass changes at the Pathhead site. The fact that the experiments were carried out at a field scale means that starting values were inevitably different - this is difficult to overcome in this type of systems experiment. Data regarding earthworms are only available for 1992 (samples were taken before the start of the experiment) and 1995 and 1997 (samples were taken prior to the harvesting of that year's crop). It should be noted that the cultivations, considered an important factor with regard to effects on soil fauna (Edwards, 1984), are the same on both the conventional and integrated systems at Pathhead. Other sites have opted for non-inversion tillage on their integrated plots where possible, a practice which is believed to be less detrimental to earthworm populations. Nevertheless, this status quo in terms of cultivation practices at Pathhead does not explain the increase in earthworm biomass on the conventional system compared with the small reduction in overall biomass on the integrated system. However, these differences could perhaps be explained by changes in the amount of organic material returned to the soil under the two systems given the differences in crop output. Differences that are apparent are the increase and higher earthworm biomass in the set-aside phases after wheat in both systems; the lowest earthworm biomasses occur in the wheat and oilseed rape phases of the rotations.

22 In determining the economic value of earthworms, it is assumed that the agricultural use value of earthworms in terms of soil quality equates to the difference between the cost of ploughing and subsequent cultivation and minimal tillage practices including direct drilling. The relevant costs per hectare are $£ 90$ for ploughing including the associated seedbed preparation, between $£ 40$ and $£ 80$ for minimal tillage, and $£ 30$ for direct drilling (Nix, 1996). The difference between the two practices therefore ranges from $£ 10$, the difference between ploughing and the most costly minimal tillage system, to $£ 60$ the difference between ploughing and direct drilling. To equate this to changes in earthworm biomass a baseline population is required. In certain circumstances, earthworms are bought 
1 have only occurred during the periods of reclamation of land for permanent grassland. Where soil

2 plugs, containing approximately $0.1 \mathrm{~kg}$ of earthworms, are bought in, the maximum number of plugs

3 that would be used per hectare would be 1250 thus giving rise to, based on a zero population of

4 earthworms at the outset, an earthworm biomass of $125 \mathrm{~kg}$. This can be taken as the baseline amount required. Dividing the difference in cost between ploughing and drilling (£60) by the baseline earthworm biomass required in terms of basic soil structuring requirements $(125 \mathrm{~kg})$ gives a value of $£ 0.48$ per kilogram of earthworm. Alternatively, taking the lower value of $£ 10$, the difference between ploughing and minimal tillage, gives a value of $£ 0.08$ per kilogram of earthworm. Taking the changes per hectare in each of the two systems between 1992 and 1995, i.e. an increase of 308 kilograms on the conventional and a reduction of 278 kilograms on the integrated, gives an additional benefit of $£ 147.84$

11 and damage cost of $£ 133.44$ respectively at the higher value, or a benefit of $£ 24.64$ and damage cost of $£ 22.24$ at the lower value.

\subsubsection{Nitrate loss}

Table 5 provides information on the nitrate residues at Pathhead from samples taken at a depth of $90 \mathrm{~cm}$ in the autumn of each year. Data for this are only available for 1995, 1996 and 1997 as no autumn sampling was undertaken in 1993 and 1994. The data indicate excess nitrate in the soil which runs the risk of loss from the system over the winter period. As can been seen from the data, residues in the conventional system are greater than that on the integrated system. Substantial differences occur, first, after set-aside in 1995 favouring the integrated system, although in the following year after winter wheat the reverse is true; and second, after oilseed rape in all three years. A notable difference also occurs in 1995 and 1996 between the barley crops of the two systems. Winter oilseed rape on the conventional system has the highest residues in all years, whereas in the integrated system the highest residues occur in the wheat phases. The lowest residues tend to be in the set-aside and barley phases of both systems.

27 The economic value of these nitrate residues, all of which are assumed to have been leached into surface or groundwater courses, can be related to the damage it causes to water quality and the cost of reparation of that damage. In the case of ground water this equates to the cost of removal of nitrates from the water when it is abstracted for drinking water. In the case of surface water, this equates to the 
1 cost associated with the damage to commercial fish stocks as a result of eutrophication although estimates of this value may be more difficult to calculate.

3 An initial value, based on ground water costs only, is determined from United States data (Panel on

4 Nitrates, 1978) converted to pounds sterling per kilogram and updated for inflation but not for advances or differences in UK technology. The Panel on Nitrates (1978) provide five estimates regarding the

6 removal of nitrates from polluted water based on different approaches to treatment. Taking the average treatment cost of three of the approaches (denitrification, chlorination, and ion exchange), which are similar in cost and also in the effectiveness of removal of nitrate (70-95\%), gives rise to an average treatment cost of $£ 2.49$ per kilogram of $\mathrm{N}$. Two other processes are ignored, nitrification and electrodialysis, as they remove less than $50 \%$ of the nitrate within the water. This treatment cost can then be applied to the nitrate residues. However, the cost is not applied to all the available residue but to levels above a given threshold. This recognises that there is some naturally occurring leakage of nitrate from the system, and also that that the environment has the ability to assimilate a certain amount of waste in the form of pollution before it becomes adversely affected. Two thresholds have been put forward. First, a threshold of $4 \mathrm{~kg}$ which has been suggested as the maximum amount of leakage that occurs from undisturbed natural ecosystems (Gosz, 1981; Melillo, 1981). Second, threshold levels which relate the losses of nitrate residues to the concentrations in the receiving water using the EU limit as a reference point, concerns over drinking water quality having led to the European Community imposing a limit of $50 \mathrm{mg} \mathrm{l}^{-1}$ for nitrate in potable water (Council of the European Communities, 1980).

20 Concentrations above this limit incur a cost, whereas concentrations below this limit do not incur a cost.

21 The limit used, although arbitrary, can be justified in that it is a well-documented, recognised, legalistic 22 reference point and is a value which has received considerable attention regarding the relationship 23 between nitrate loss and the resultant concentrations in the receiving water in relation to soil type, 24 climate and the quality of that receiving water. Williams (1990), for example, has modelled nitrate loss in relation to the concentrations in the receiving water using data on the water supply system, the process of nitrate leaching and farming land use. Included in the calculations are data on rainfall, soil type and rock strata, and water volume, abstraction, flows and hydrological pressure. This model has provided three ranges of maximum nitrate loss allowable to meet the EU limit: $11-22 \mathrm{~kg}$ for the area around East Anglia; 22-33kg for North East England, the Midlands, the South East, and the far eastern 
1 bound estimates that are used as thresholds in this analysis; for the Pathhead site in Scotland this allows

2 a loss of $33 \mathrm{~kg}$ of nitrate before a cost is incurred. Therefore, in the conventional rotation at Pathhead

3 during 1995, assuming a loss of $60 \mathrm{~kg}$ (93kg minus $33 \mathrm{~kg}$ allowable), the cost of the resultant damage

4 would be $£ 149.40$. Similarly, for the integrated rotation in that year the cost would be $£ 72.21$.

5 Alternatively, with a threshold of $4 \mathrm{~kg}$, the cost would be $£ 221.61$ for the conventional system and

$6 £ 144.42$ for the integrated system.

\subsubsection{Beetle and spider numbers}

Table 6 provides information on the final indicator of environmental impact, the number of invertebrates (Carabidae, Staphylinidae, Linysiidae, Lycosidae) within each system. In each field, and for both farming systems, two transects of five pitfall traps were used to collect data on invertebrate activity. The traps were placed $30 \mathrm{~m}$ in from a common boundary and then spaced at $10 \mathrm{~m}$ intervals thereafter. The pitfall traps were partly filled with water and detergent and operated for 10 day periods during the winter and 5 day periods during the summer for the length of each crop's growing period.

15 The results show that there is no obvious pattern in either system, with the integrated system in comparison with the conventional showing marginally higher numbers for four years and lower numbers in one year. The more obvious pattern is the swing between increases and reductions across the years in both systems, and there is some indication that the set-aside phases lead to greater invertebrate numbers, whereas oilseed rape gives rise to the least numbers.

20 In terms of their economic value, an estimate could be based on information on pesticide costs 21 assuming that the invertebrates are of quantifiable value to the individual farmer as a natural predator of 22 crop pests such as aphids, and that an increase in their number will reduce the farmer's reliance on 23 pesticides and as a result pesticide costs. To do this, the average cost of application of an insecticide 24 needs to be given and equated with a baseline population of beneficial invertebrates required to replace 25 that insecticide. Dividing the number in the required baseline population by the cost of the pesticide would give a measure of invertebrate value. This should realistically be based on a population per one

27 hundred or one thousand, the resultant value being applied to changes (flow values) in that population 28 as opposed to static (stock) numbers. Although data are available on insecticide costs - an appropriate 29 value would be $£ 15$ per hectare (Nix (1996), taking the cost of an insecticide containing the active 30 ingredient pirimicarb, estimates the approximate cost of an application from £13-15 in cereals and from 
$1 £ 15-22$ in oilseed rape) - the information on the baseline number of invertebrates is not. Furthermore,

2 relating the number of invertebrates caught in pitfall traps (a measure of activity) to a given population

3 per hectare is not possible. A similar approach based on their value as part of the food chain would also

4 require an estimate of numbers related to population as opposed to activity. Given the current difficulty

5 in providing a suitable estimate of value, a record of the physical numbers caught in pitfall traps is

6 presented. Individuals may wish to make a subjective decision about the trade-offs between this indicator (biodiversity), financial returns, earthworm biomass (soil quality) and nitrate loss (water quality).

\section{Discussion and conclusions}

11 Combining the information on the financial results with environmental impact gives rise to a system of integrated environmental and economic accounts (see Table 7). It indicates both the financial and environmental values for the five years of the experimental rotation at the Pathhead site. First, the traditional financial account is given, showing that the integrated system, in this example, is financially viable when compared to conventional farming practices in that it has a higher net margin. Second, the values for the environmental impact are included. In this example, the minimum environmental values given previously (see sections 4.2.2., 4.2.3. and 4.2.4.) are used. Counter-intuitively, in environmental terms, the integrated system appears to be less beneficial to the environment in terms of soil quality (earthworm biomass), and the results are inconclusive for the effect of the two systems on fauna (invertebrate numbers). These indicators suggest that although inputs into the environment can be measured directly at the time of occurrence, the impacts that may then indirectly arise from those inputs may take a longer time to materialise. However, nitrate residues, used as an estimate of potential leaching, are an indicator that provides results that would be expected, with the integrated system appearing less damaging in terms of water quality. Overall, both the conventional and integrated margins are reduced as a result of environmental impacts, although the difference between the two systems increases indicating that the integrated system, despite its negative impact on earthworm biomass, is of greater benefit to the environment than when compared with the conventional system. Despite these observations, statistical analysis of the data using analysis of variance reveals that there is no significant difference between the two systems with respect to Net Margins, beetles and spiders, 
1 farming system in order to extract the statistical significance from the results poses a problem. The quantitative information available on earthworm interaction with other components of the system is insufficient, particularly in terms of time series. Thus, it would not be wise to attempt to draw firm conclusions from the above analyses, other than to accept that at this stage the aim has been to develop a method of comparison not necessarily to obtain absolute values.

6 Regarding the use of environmental and natural resource accounting it can be said that it has the potential to provide a format for allowing the trade-off between financial and environmental impacts, and between the differing environmental impacts themselves. The example given above illustrates the application of the accounting framework to the comparison of different farming systems, achieved through the definition of the costs and benefits of agri-environmental measures, both positive and 11 negative. The above proposed framework is also flexible enough to incorporate data regarding other environmental impacts as they become available and, even without complete valuation, presents the data in a format which can aid the understanding of agricultural and environmental trade-offs.

14 Considering the indicators used, it should be noted that the earthworm data relates to agricultural use values only. Non-use / intrinsic values would need to be included to give a more accurate estimate of their value; the approach to the calculation of these values would perhaps involve the use of CVM (Cummings et al., 1986) or consultation with experts using the Delphi technique. Such techniques may also be useful in overcoming the problem of the valuation of biodiversity using the data on invertebrates. Values for the use of nitrates are already reflected in the accounts as the additional input costs for nitrogen fertiliser. The figures calculated for the treatment cost of polluted water represent the

21 additional cost to society of that pollution. A limitation concerning the use of such indicators to assess the environmental impacts of agricultural production systems is that the choice of indicator may inevitably lead to some form of bias, favouring one or other of the systems under review. This, of course, depends on the nature of the indicators used, and is a problem which is also applicable to other methods which use similar approaches to examine environmental impact. A final limitation of the approach are the problems, highlighted by the information on invertebrates, regarding the provision, measurement and valuation of data.

28 Nevertheless, the above approach has the potential to provide insights for both farm level decision making and macro level policy formulation, and is of particular relevance to sustainable farming systems where the objectives are to achieve long term financial viability with minimal adverse impacts 
1 on the environment. Furthermore, although the current version of the model is only suitable for short-

2 term static analysis, given additional data, the longer term implications of both conventional and

3 integrated arable systems could be evaluated. Even without this additional data, the process of

4 recording and valuing the environmental information as it becomes available can provide valuable insights regarding the impacts of differing agricultural systems on the environment.

\section{Acknowledgements}

The authors would like to thank the site managers and others involved in the LINK-IFS project for their help in provision of data, in particular, Alastair Drysdale and others working at the Pathhead site.

10 The Pathhead site is located on land owned by the Prestonhall Farming Company and managed by Mr.

11 W. Gray. Their co-operation in this project is also appreciated. Nevertheless, the opinions expressed here and conclusions reached are solely the responsibility of the authors. Financial support from the

13 MAFF Open Contracting Scheme (CSA 2935) is also gratefully acknowledged.

\section{References}

16 Addiscott, T.M., Whitmore, A.P., Powlson, D.S., 1991. Farming, Fertilisers and the Nitrate Problem. 17 CAB International, Wallingford.

18 Ahmad, Y.J., El Serafy, S., Lutz, E.L., 1989. Environmental Accounting for Sustainable Development. 19 The World Bank, Washington DC.

20 Alfsen, K.H., Torstein, B., Lorentsen, L., 1987. Natural Resource Accounting and Analysis: the 21 Norwegian Experience 1978-1986. Central Bureau of Statistics, Oslo, Norway.

22 Ayres, R.U., Kneese, A.V., 1969. Production, consumption and externalities. American Economic 23 Review, 59, 282-297.

24 Bartelmus, P., 1989. Environmental accounting and the system of national accounts. In: Ahmad, Y.J., 25 El Serafy, S., Lutz, E.L. (Eds), Environmental Accounting for Sustainable Development. The World 26 Bank, Washington DC.

27 Bisset, R., 1983. A critical survey of methods for environmental impact assessment. In: O'Riordan, T., 28 Turner, R. (Eds), An Annotated Reader in Environmental Planning and Management. Urban and 29 Regional Planning Series, 30. Pergamon, Oxford. 
Bisset, R., 1988. Developments in EIA methods. In: Wathern, P. (Ed), Environmental Impact Assessment, Theory and Practice. Unwin Hyman, London.

Council of the European Communities, 1980. EEC Directive Relating to the Quality of Water Intended for Human Consumption, 80/778/EEC, available in DOE circular 20/82, HMSO 1982.

Cummings, R.G., Brookshire, D.S., Schulze, W.D., 1986. Valuing Environmental Goods: an Assessment of the Contingent Valuation Method. Rowman and Littlefield, USA.

Dee, N., Baker, J.K., Drobny, N.L., Duke, K.M., Fahringer, D.C., 1972. An Environmental Evaluation System for Water Resource Planning. National Technical Information Service, Report PB-208822, Springfield. Vancouver.

10 Department of the Environment, 1986. River Quality in England and Wales - 1985. HMSO, London.

11 Department of the Environment, 1996. Indicators of Sustainable Development for the United Kingdom. HMSO, London.

13 Dixon, J.A., Sherman, P.B., 1990. Economics of Protected Areas: a New Look at Benefits and Costs. 14 Earthscan, London.

15 Edwards, C.A., Lofty, J.R., 1972. Biology of Earthworms. Chapman and Hall, London.

16 Edwards, C.A., 1984. Changes in agricultural practice and their impact on soil organisms. In: Jenkins, 17 D. (Ed), Agriculture and the environment, Proceedings of ITE symposium no. 13. NERC, 18 Cambridge.

19 Edwards, C.A., Bohlen, P.J., 1996. Biology and Ecology of Earthworms. Chapman and Hall, London.

20 El Titi, A., Boller, E.F., Gendrier, J.P., 1993. Integrated production - principles and technical 21 guidelines. 10BC/WPRS Bulletin 16, (1).

22 Fisher, N.M., Richards, M.C., Drysdale, A.D., 1996. The contribution of spring crops to integrated crop 23 rotations. Aspects of Applied Biology, 47, 343-348.

24 Glasson, J., Therivel, R., Chadwick, A., 1994. Introduction to Environmental Impact Assessment. UCL 25 Press, London.

26 Gosz, J.R., 1981. Nitrogen cycling in coniferous forests. In: Clark, F.E., Rosswall, T. (Eds) Terrestrial 27 Nitrogen Cycles: Processes, Ecosystem Strategies and Management Impacts. Stockholm Ecology 28 Bulletin.

29 Hanley, N., Spash, C., Walker, L, 1994. Problems in Valuing the Benefits of Biodiversity Protection. 30 Discussion Paper No. 94/8. Economics Department, University of Stirling. 
1 James, D., 1994. The Application of Economic Techniques in Environmental Impact Assessment. Kluwer Academic, London.

Kelly, T.C., Lu, Y.C., Teasdale, J., 1996. Economic-environmental trade-offs among alternative crop rotations. Agriculture, Ecosystems and the Environment, 60, 17-28.

Lee, K.E., 1985. Earthworms: their Ecology and Relationships with Soil and Land Use. Academic Press, London.

Leontief, W., 1970. Environmental repercussions and economic structure: an input-output approach. Review of Economics and Statistics, 52, 262-271.

Leopold, L.B., Clarke, F.E., Hanshaw, B.B., Balsley, J.R., 1971. A Procedure for Evaluating

10 Environmental Impact. Geological Survey Circular 645. Government Printing Office, Washington.

11 Lutz, E., 1993. Toward Improved Accounting for the Environment. The World Bank, Washington DC.

12 Meister, A.D., 1990. Economic Analysis of Environmental Impacts and Issues. Discussion Paper in

13 Natural Resource Economics No. 14. Department of Agricultural Economics and Business, Massey

14 University, Palmerston North, New Zealand.

15 Melillo, J.M., 1981. Nitrogen cycling in deciduous forests. In: Clark, F.E., Rosswall, T. (Eds) 16 Terrestrial Nitrogen Cycles: Processes, Ecosystem Strategies and Management Impacts. Stockholm 17 Ecology Bulletin.

18 Mishan, E. J., 1975. Cost Benefit Analysis: an Informal Introduction. Allen and Unwin, London.

19 Nix, J., 1996. Farm Management Pocketbook, $27^{\text {th }}$ Edition. Wye College, University of London.

20 OECD, 1997. Environmental Indicators for Agriculture. OECD, Paris.

21 Ogilvy, S.E., Turley, D.B., Cook, S.K., Fisher, N.M., Holland, J., Prew, R., Spink, J., 1994. Integrated 22 farming - putting together systems for farm use. Aspects of Applied Biology, 40, 53-61.

23 Panel on Nitrates of the Co-ordinating Committee for the Scientific and Technical Assessments of 24 Environmental Pollutants, 1978. Nitrates: an Environmental Assessment. National Academy of 25 Sciences. Washington DC.

26 Park, J., Farmer, D.P., Bailey, A.P., Keatinge, J.D.H., Rehman, T., Tranter, R.B., 1997. Integrated 27 Arable Farming Systems and their potential uptake in the UK. Farm Management, 9, 483-494.

28 Pearce, D., Markandya, A., Barbier, E.B., 1989a. Blueprint for a Green Economy. Earthscan, London. 29 Pearce, D.W., Markandya, A., Barde, J-Ph., 1989b. Environmental Policy Benefits: Monetary $30 \quad$ Valuation. OECD, Paris. 
1 Romero, C.. Rehman, T., 1987. Natural resource management and the use of multiple criteria decisionmaking techniques: a review. European Review of Agricultural Economics, 14, 61-89.

Romero, C., Rehman, T., 1989. Multi-Criteria Analysis for Agricultural Decisions. Elsevier, Oxford.

Sorenson, J.C., 1971. A Framework for Identification and Control of Resource Degradation and Conflict in the Multiple Use of the Coastal Zone. Department of Landscape, University of California,

6 Berkley.

Spash, C., Hanley, N., 1994. Preferences, Information and Biodiversity Preservation. Discussion Papers in Ecological Economics, No. 94/1. University of Stirling.

Taylor, A.E.B., O’Callaghan, P.W., Probert, S.D., 1993. Energy audit of an English farm. Applied 10 Energy, 44, 315-335.

11 Theys, J., 1989. Environmental accounting in development policy: the French experience. In: Ahmad, 12 Y.J. El Serafy, S., Lutz, E.L. (Eds) Environmental Accounting for Sustainable Development. The 13 World Bank, Washington DC.

14 United Nations, 1993. Integrated Environmental and Economic Accounting. Series F, Number 61. 15 United Nations, New York.

16 Wathern, P., 1984. Ecological modelling in impact analysis. In: Roberts, R.D., Roberts, T.M. (Eds), 17 Planning and Ecology. Chapman and Hall, London.

18 Williams, A.J., 1990. Using a modelling approach to demonstrate and quantify trade-offs in the nitrate 19 issue as an aid to making policy decisions. In: van der Noort, P.C. (Ed) Costs and Benefits of 20 Agricultural Policies and Projects. Proceedings $22^{\text {nd }}$ Symposium EAAE 1989. Amsterdam.

21 Wossink, G.A.A., Buys, J.C., Jurgens, C.R., de Snoo, G.R. and Renkema, J.A., 1996. What, how and 22 where: nature conservation and restoration in sustainable agriculture. VIIth European Congress of 23 Agricultural Economists, Redefining the Roles for European Agriculture, Edinburgh, September 3-7, 241996. 
$1 \quad$ Table 1

2 Comparison of financial results ( $£ \mathrm{ha}^{-1}$, current prices) for the conventional and integrated systems at

3 the Pathhead, Scotland site 1993-1997

\begin{tabular}{|c|c|c|c|c|c|c|c|c|c|c|c|c|}
\hline & \multicolumn{2}{|c|}{1993} & \multicolumn{2}{|c|}{1994} & \multicolumn{2}{|c|}{1995} & \multicolumn{2}{|c|}{1996} & \multicolumn{2}{|c|}{1997} & \multicolumn{2}{|c|}{ Rotation } \\
\hline & $\mathrm{CFS}^{\mathrm{a}}$ & $\mathrm{IFS}^{\mathrm{b}}$ & CFS & IFS & CFS & IFS & CFS & IFS & CFS & IFS & CFS & IFS \\
\hline Output $^{c}$ & 775 & 711 & 820 & 838 & 1218 & 1161 & 1138 & 1111 & 899 & 789 & 4851 & 4610 \\
\hline Seed costs & 48 & 49 & 42 & 44 & 41 & 42 & 42 & 47 & 42 & 42 & 215 & 223 \\
\hline Fertiliser & 69 & 56 & 74 & 54 & 85 & 72 & 104 & 91 & 118 & 82 & 449 & 355 \\
\hline Pesticides & 56 & 33 & 50 & 16 & 76 & 28 & 75 & 36 & 62 & 35 & 319 & 148 \\
\hline Other costs $^{\mathrm{d}}$ & 16 & 16 & 11 & 15 & 6 & 2 & 7 & 7 & 6 & 7 & 46 & 47 \\
\hline Total variable costs ${ }^{\mathrm{e}}$ & 189 & 153 & 177 & 129 & 209 & 144 & 228 & 180 & 228 & 168 & 1030 & 774 \\
\hline Gross margin & 586 & 557 & 643 & 709 & 1009 & 1017 & 910 & 931 & 671 & 622 & 3820 & 3837 \\
\hline Operating costs ${ }^{\mathrm{f}}$ & 220 & 220 & 178 & 168 & 190 & 173 & 201 & 181 & 200 & 175 & 989 & 918 \\
\hline Net margin & 365 & 337 & 465 & 541 & 819 & 843 & 710 & 750 & 472 & 446 & 2831 & 2918 \\
\hline
\end{tabular}

$4 \quad{ }^{\mathrm{a}}$ Conventional farming system.

$5 \quad$ b Integrated farming system.

$6{ }^{c}$ Yield multiplied by the average November price (from the HGCA Weekly Digest).

$7 \quad{ }^{\mathrm{d}}$ Other costs include growth regulators, desiccant and miscellaneous costs.

$8{ }^{\mathrm{e}}$ Total variable costs comprise seed costs, fertiliser, pesticide and other costs.

$9{ }^{\mathrm{f}}$ Operating costs include primary cultivations, fertiliser and agrochemical application, swathing,

10 harvesting and miscellaneous drying costs.

11 
$1 \quad$ Table 2

2 Comparison of financial results $\left(£ \mathrm{ha}^{-1}\right.$, societal value) for the conventional and integrated systems at

3 the Pathhead, Scotland site 1993-1997

\begin{tabular}{|c|c|c|c|c|c|c|c|c|c|c|c|c|}
\hline & \multicolumn{2}{|c|}{1993} & \multicolumn{2}{|c|}{1994} & \multicolumn{2}{|c|}{1995} & \multicolumn{2}{|c|}{1996} & \multicolumn{2}{|c|}{1997} & \multicolumn{2}{|c|}{ Rotation } \\
\hline & $\mathrm{CFS}^{\mathrm{a}}$ & IFS $^{b}$ & CFS & IFS & CFS & IFS & CFS & IFS & CFS & IFS & CFS & IFS \\
\hline Output $^{c, d}$ & 656 & 574 & 680 & 659 & 1198 & 1080 & 875 & 830 & 695 & 561 & 4103 & 3703 \\
\hline Total variable costs ${ }^{\mathrm{d}}$ & 227 & 179 & 217 & 157 & 257 & 176 & 281 & 221 & 281 & 205 & 1263 & 938 \\
\hline Gross margin & 428 & 395 & 463 & 502 & 942 & 904 & 594 & 609 & 414 & 356 & 2841 & 2765 \\
\hline Operating costs ${ }^{\mathrm{d}}$ & 269 & 268 & 215 & 204 & 232 & 211 & 245 & 221 & 245 & 214 & 1206 & 1118 \\
\hline Net margin & 160 & 127 & 247 & 298 & 710 & 692 & 349 & 388 & 169 & 142 & 1635 & 1647 \\
\hline
\end{tabular}

$4 \quad{ }^{\mathrm{a}}$ Conventional farming system.

$5 \quad$ b Integrated farming system.

$6 \quad{ }^{\mathrm{c}}$ At world prices (from HGCA Weekly Digest) and excluding area payment.

$7 \quad{ }^{\mathrm{d}}$ Excludes set-aside phase; (otherwise, definition of costs are as for Table 1).

8

9 
1 Table 3

2 Comparison of fertiliser $\left(\mathrm{kg} \mathrm{N} \mathrm{ha}^{-1}\right)$ and pesticide use (units $\left.{ }^{\mathrm{c}}\right)$ at the Pathhead, Scotland site for the

3 conventional and integrated systems, 1993-1997

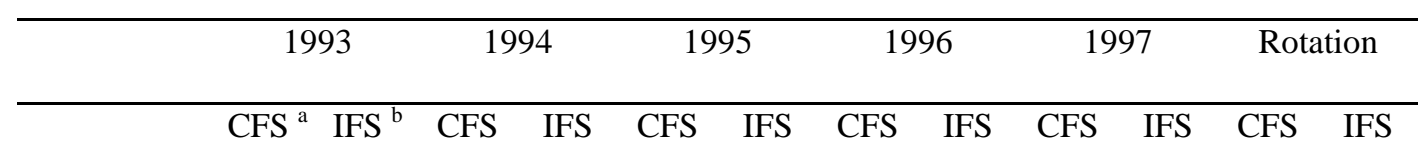

$\begin{array}{lrlllllllllll}\text { Fertiliser } & 144 & 115 & 164 & 115 & 171 & 122 & 173 & 127 & 179 & 126 & 832 & 605 \\ & & & & & & & & & & & & \\ \text { Pesticides } & 4.80 & 3.45 & 3.36 & 2.29 & 5.98 & 2.89 & 5.73 & 3.19 & 4.91 & 3.36 & 24.79 & 15.18\end{array}$

$4 \quad{ }^{\mathrm{a}}$ Conventional farming system.

$5 \quad$ b Integrated farming system.

$6{ }^{\mathrm{c}}$ The maximum amount (in grams) of an active ingredient recommended for arable crops.

7

8 
1 Table 4

2 Comparison of earthworm biomass changes $\left(\mathrm{kg} \mathrm{ha}^{-1}\right)$ at the Pathhead, Scotland site for the conventional

3 and integrated systems, 1992-1997

\begin{tabular}{|c|c|c|}
\hline & $\mathrm{CFS}^{\mathrm{a}}$ & IFS $^{b}$ \\
\hline 1992 biomass (kg) & & \\
\hline 1995 biomass (kg) & & \\
\hline 1997 biomass $(\mathrm{kg})$ & & \\
\hline $1992-1995$ change in biomass $(\mathrm{kg})$ & & \\
\hline Valued @8p kg ${ }^{-1}(£)$ & & \\
\hline Valued@ $@ 8$ p kg-1 (£) & & \\
\hline $1995-1997$ change in biomass $(\mathrm{kg})$ & & \\
\hline Valued @8p kg ${ }^{-1}(£)$ & & \\
\hline Valued@ 48p kg-1 (£) & & \\
\hline $1992-1997$ change in biomass $(\mathrm{kg})$ & & \\
\hline Valued @8p kg-1 (£) & & \\
\hline Valued@ @8p kg-1 (£) & & \\
\hline
\end{tabular}

$4 \quad{ }^{\mathrm{a}}$ Conventional farming system.

$5 \quad$ b Integrated farming system.

6

7 
1 Table 5

2 Comparison of soil nitrate residues at $0-90 \mathrm{~cm}$ depth $\left(\mathrm{kg} \mathrm{N} \mathrm{ha}^{-1}\right)$ at the Pathhead, Scotland site in the

3 conventional and integrated systems, 1995-1997

$\mathrm{CFS}^{\mathrm{a}} \quad \mathrm{IFS}^{\mathrm{b}}$

1995 residue $(\mathrm{kg})$

1996 residue $(\mathrm{kg})$

108

1997 residue $(\mathrm{kg})$

103

Rotational residue, 1995-1997 (kg)

304

1995 residue valued @ $2.49 \mathrm{~kg}^{-1}$ using 4kg threshold (£)

221.61

141.93

1996 residue valued @ $2.49 \mathrm{~kg}^{-1}$ using 4kg threshold (£)

$258.96 \quad 179.28$

1997 residue valued @ $2.49 \mathrm{~kg}^{-1}$ using 4kg threshold (£)

246.51

179.28

1995-1997 residue valued @ $2.49 \mathrm{~kg}^{-1}$ using 4kg threshold (£)

747.00

1995 residue valued @ $2.49 \mathrm{~kg}^{-1}$ using 33kg threshold (£)

149.40

1996 residue valued @ $2.49 \mathrm{~kg}^{-1}$ using $33 \mathrm{~kg}$ threshold (£)

$186.75 \quad 107.07$

1997 residue valued @ $2.49 \mathrm{~kg}^{-1}$ using $33 \mathrm{~kg}$ threshold (£)

$173.30 \quad 107.07$

1995-1997 residue valued @ $2.49 \mathrm{~kg}^{-1}$ using $33 \mathrm{~kg}$ threshold (£)

$674.79 \quad 448.20$

$4 \quad{ }^{\mathrm{a}}$ Conventional farming system.

$5 \quad$ b Integrated farming system.

6

7 
1 Table 6

2 Comparison of mean number of invertebrates (beetles and spiders) per pitfall trap per day over the crop

3 growing period at the Pathhead, Scotland site for the conventional and integrated systems, 1992-1997

\begin{tabular}{lcc}
\hline & CFS $^{\text {a }}$ & IFS $^{b}$ \\
\hline Number of invertebrates & 1.50 & 1.52 \\
1992 & 0.55 & 0.64 \\
1993 & 5.41 & 5.22 \\
1994 & & 1.21 \\
1995 & 0.96 & 1.52 \\
1996 & 1.37 & 1.29
\end{tabular}

Change in the number of invertebrates

1992-1993

1993-1994

1994-1995

1995-1996

1996-1997

1992-1997

$\begin{array}{ll}-0.95 & -0.88 \\ +4.86 & +4.59 \\ -4.45 & -4.02 \\ +0.41 & +0.31 \\ -0.20 & -0.23 \\ -0.33 & -0.23\end{array}$

$4 \quad{ }^{\mathrm{a}}$ Conventional farming system.

$5 \quad$ b Integrated farming system.

6

7 
$1 \quad$ Table 7

2 Comparison of financial and economic results ( $£ \mathrm{ha}^{-1}$, current prices) at the Pathhead, Scotland site for

3 the conventional and integrated systems, 1992-1997

\begin{tabular}{|c|c|c|}
\hline & \multicolumn{2}{|c|}{ Rotation } \\
\hline & $\mathrm{CFS}^{\mathrm{a}}$ & IFS $^{b}$ \\
\hline Output & 4850.50 & 4610.80 \\
\hline Seed costs & 215.90 & 223.40 \\
\hline Fertiliser & 449.48 & 354.89 \\
\hline Pesticides & 319.04 & 147.60 \\
\hline Other variable costs & 46.00 & 46.86 \\
\hline Total variable costs & 1030.46 & 774.19 \\
\hline Gross margin & 3820.07 & 3836.61 \\
\hline Operating costs & 988.71 & 918.48 \\
\hline Net margin & 2831.36 & 2918.13 \\
\hline Earthworm biomass & +28.88 & -9.92 \\
\hline Nitrate loss ${ }^{c}$ & -674.79 & -448.20 \\
\hline Environmentally adjusted net margin & 2185.45 & 2460.01 \\
\hline Invertebrate numbers & -0.33 & -0.23 \\
\hline${ }^{\mathrm{a}}$ Conventional farming system. & & \\
\hline${ }^{\mathrm{b}}$ Integrated farming system. & & \\
\hline${ }^{\mathrm{c}}$ Figures for 1995-1997 only. & & \\
\hline
\end{tabular}


1 Table 8

2 Statistical significance (P values) for the financial and environmental main and interaction effects at the

3 Pathhead, Scotland site, 1993-1997

\begin{tabular}{|c|c|c|c|c|}
\hline Source & Net margin & Nitrate residues & Earthworm biomass & Beetles and spiders $^{\mathrm{a}}$ \\
\hline System & 0.993 & 0.263 & 0.245 & 0.473 \\
\hline Year & 0.000 & 0.664 & 0.940 & 0.000 \\
\hline Crop & 0.000 & 0.033 & 0.041 & 0.000 \\
\hline Year by system & 0.938 & - & 0.703 & - \\
\hline Year by crop & 0.002 & - & 0.131 & - \\
\hline
\end{tabular}

4 - Insufficient data

5 a The effects of field and month of collection for beetles and spiders has been removed from the data 6

7 